\title{
A bispecific aptamer sensor towards T-cell leukemia detection in the tumor microenvironment
}

Natalie Boykoff $2 \#$, Lina Freage ${ }^{1 \#}$, Jared Lenn ${ }^{4}$, and Prabodhika Mallikaratchy ${ }^{1,2,3^{*}}$.

1 Department of Chemistry, Lehman College, The City University of New York, 250 Bedford Park Blvd., West, Bronx, NY 10468, USA

2 Ph.D. Programs in Chemistry and Biochemistry, CUNY Graduate Center, 365 Fifth Avenue, New York, NY 10016, USA

${ }^{3}$ Ph.D. Program in Molecular, Cellular and Developmental Biology, CUNY Graduate Center, 365 Fifth Avenue, New York, NY 10016, USA

${ }^{4}$ The Bronx High School of Science, 75 W 205 ${ }^{\text {th }}$ Street, Bronx, NY 10468

\# Equally contributed

${ }^{*}$ To whom correspondence should be addressed: Prabodhika Mallikaratchy, Department of Chemistry, Lehman College, The City University of New York, 250 Bedford Park West, Bronx New York, NY 10468;

prabodhika.mallikaratchy@lehman.cuny.edu; Phone: 347-577-4082. 
(A)

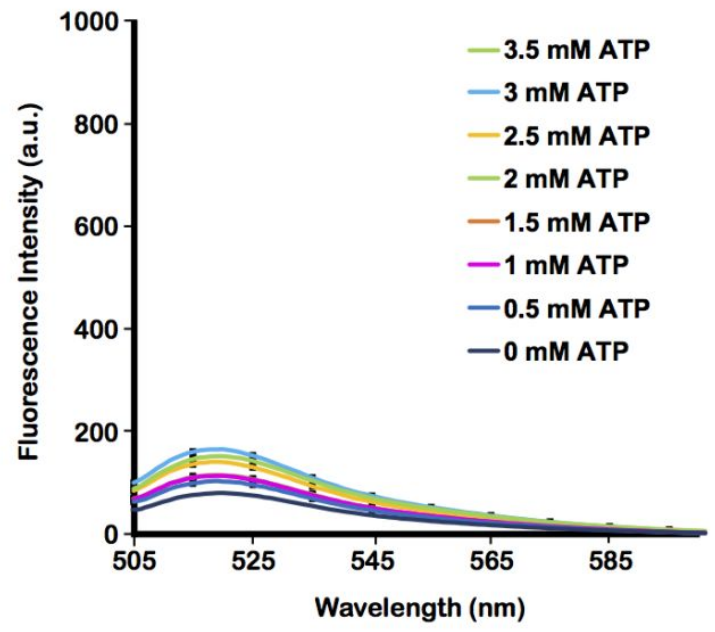

(B)

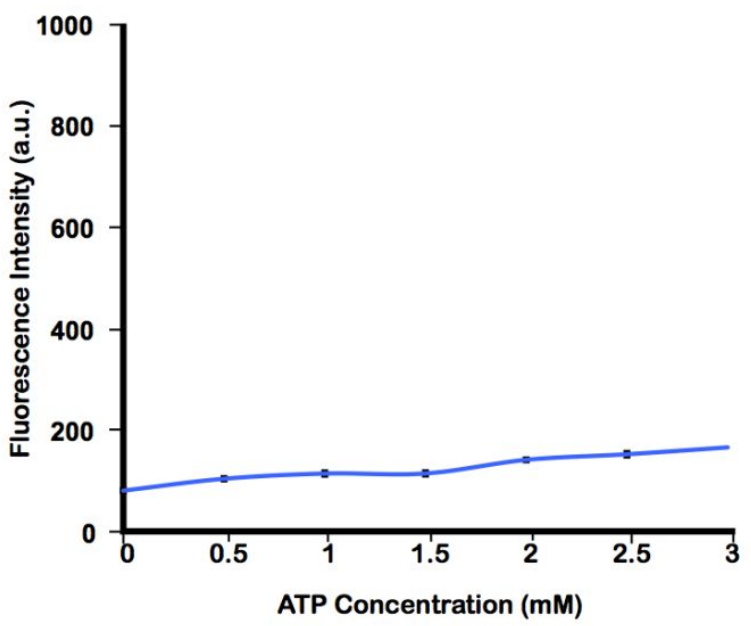

Figure S-1: Titration assay of ARTS-R1 using different concentrations of ATP. A) Fluorescence spectrum of ARTS-R1 in the absence and presence of $0.5,1,1.5,2,2.5$, 3, 3.5 and $4 \mathrm{mM}$ of ATP. B) The calibration plot of ARTS-R1 over the range of 0.5, 1, 1.5, 2, 2.5, 3, 3.5 and $4 \mathrm{mM}$ of ATP. The titration assay was done using $250 \mathrm{nM}$ ARTS-R1 prepared in $500 \mu \mathrm{L}$ of $10 \mathrm{mM}$ Tris- $\mathrm{HCl}$ with $6 \mathrm{mM} \mathrm{MgCl}_{2}, \mathrm{pH}=8.4$. The construct was subsequently folded by heating ARTS-R 1 at $95^{\circ} \mathrm{C}$ for 5 mins to denature undesirable secondary structures and then cooling to $25^{\circ} \mathrm{C}$ for 30 mins. Following this, the construct was transferred to a quartz cuvette and placed in the Cary Eclipse fluorescence spectrophotometer and the fluorescence intensity without ATP, and with $0.5,1,1.5,2$, $2.5,3,3.5$, and $4 \mathrm{mM}$ of ATP was measured. The fluorescence spectra were measured using excitation wavelength of the 6-FAM fluorophore $\lambda_{\mathrm{ex}}=495 \mathrm{~nm}$, and thus emission was scanned between $\lambda_{\mathrm{em}}=505-600 \mathrm{~nm}$. 
(A)

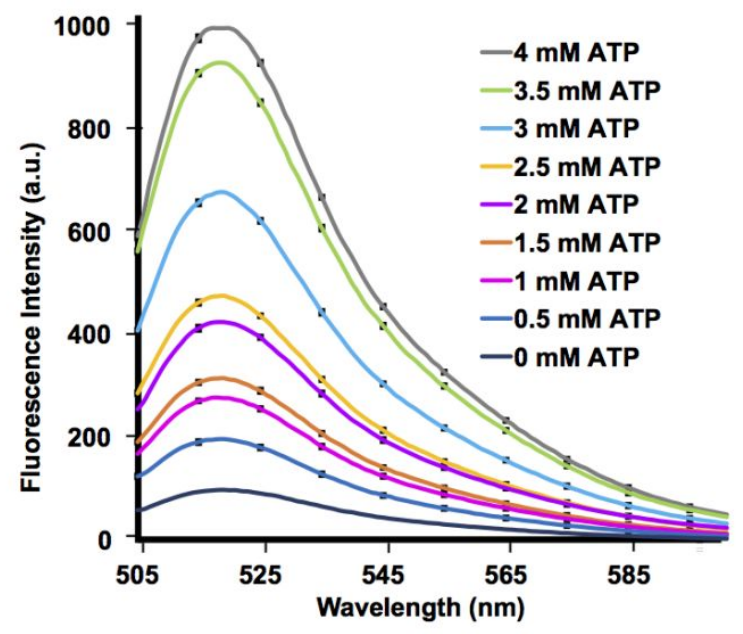

(B)

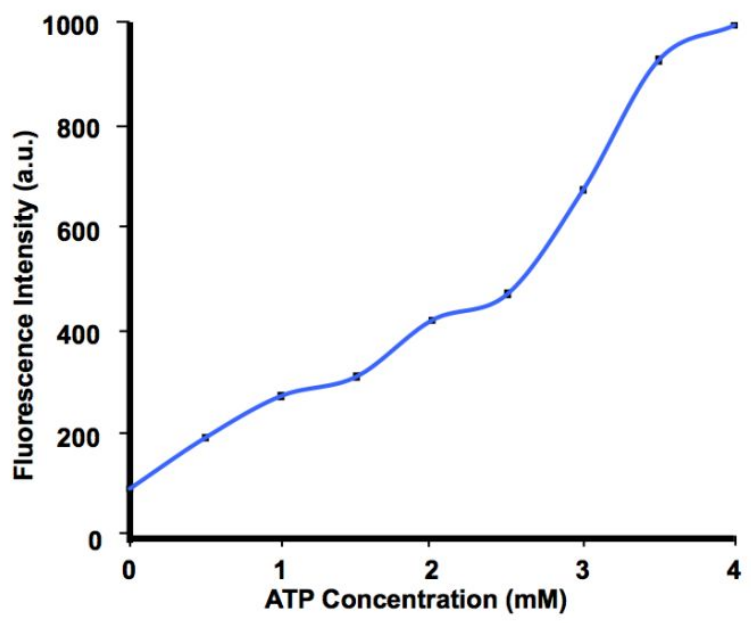

Figure S-2: Titration assay of ARTS-R2 using different concentrations of ATP. A) Fluorescence spectrum of ARTS-R2 in the absence and presence of 0.5, 1, 1.5, 2, 2.5, 3, 3.5 and $4 \mathrm{mM}$ of ATP. B) The calibration plot of ARTS-R2 over the range of $0.5,1,1.5$, $2,2.5,3,3.5$ and $4 \mathrm{mM}$ of ATP. The titration assay was done using $250 \mathrm{nM}$ of ARTS- R2 was prepared in $500 \mu \mathrm{L}$ of $10 \mathrm{mM}$ Tris- $\mathrm{HCl}$ with $6 \mathrm{mM} \mathrm{MgCl}_{2}, \mathrm{pH}=8.4$. The was folded by heating ARTS-R2 at $95^{\circ} \mathrm{C}$ for 5 mins to denature undesirable secondary structures and then cooling to $25^{\circ} \mathrm{C}$ for 30 mins. The fluorescence intensity without ATP, and with 0.5 , $1,1.5,2,2.5,3,3.5$, and $4 \mathrm{mM}$ of ATP was measured. The fluorescence spectra were measured using excitation wavelength of the 6-FAM fluorophore $\lambda_{\mathrm{ex}}=495 \mathrm{~nm}$, and thus emission was scanned between $\lambda_{\mathrm{em}}=505-600 \mathrm{~nm}$. 
(A)

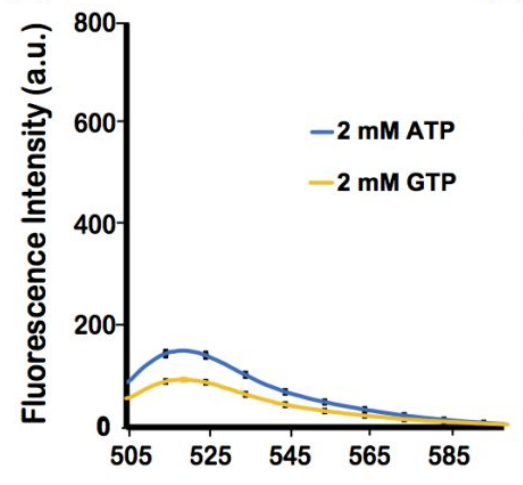

(B)

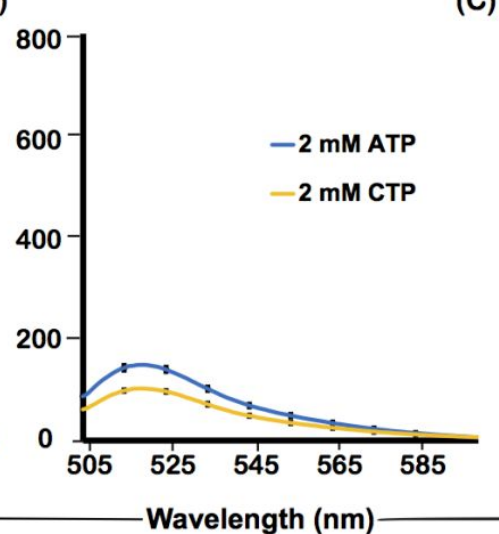

(C)

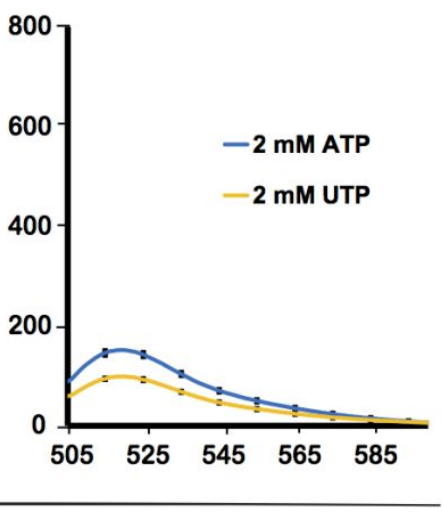

Figure S-3: Analysis of the specificity of the ARTS-R1.

A) Specificity of ARTS-R1 with $2 \mathrm{mM}$ ATP and $2 \mathrm{mM}$ CTP. B) Specificity of the ARTS-R1 with $2 \mathrm{mM}$ ATP and $2 \mathrm{mM} \mathrm{GTP}$. C) Specificity of the ARTS-R1 with 2mM ATP and 2mM UTP. The ARTS-R1 was prepared for the assay by heating at $95^{\circ} \mathrm{C}$ for 5 mins, and then cooling down to $25^{\circ} \mathrm{C}$ over 30 minutes. Four samples of $250 \mathrm{nM}$ ARTS-R1 were prepared in a final volume of $500 \mu \mathrm{L}$ in $10 \mathrm{mM}$ Tris- $\mathrm{HCl}$, with $6 \mathrm{mM} \mathrm{MgCl}_{2}, \mathrm{pH}=8.4$. Next, $2 \mathrm{mM}$ of each nucleotide (ATP, GTP, CTP and UTP) was added to respective sample. Following this, the construct was transferred to a quartz cuvette and placed in the Cary Eclipse fluorescence spectrophotometer so the fluorescence intensity of 2mM ATP, GTP, CTP and UTP could be measured. The fluorescence spectra were measured using excitation wavelength of the 6-FAM fluorophore $\lambda_{\mathrm{ex}}=495 \mathrm{~nm}$, and thus emission was scanned between $\lambda_{\mathrm{em}}=505-600 \mathrm{~nm}$. 
(A)

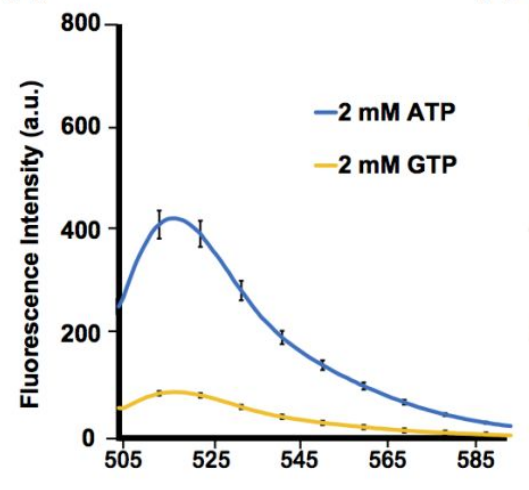

(B)

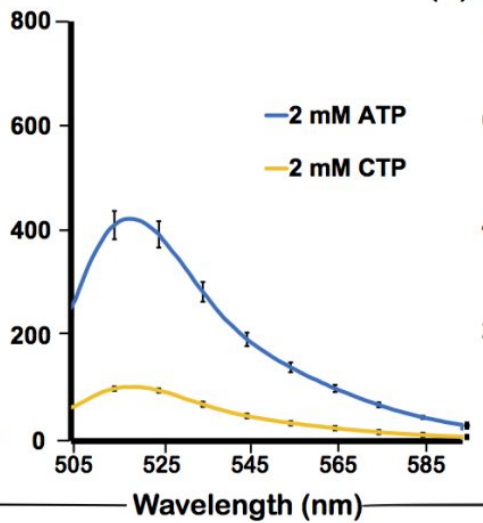

(C)

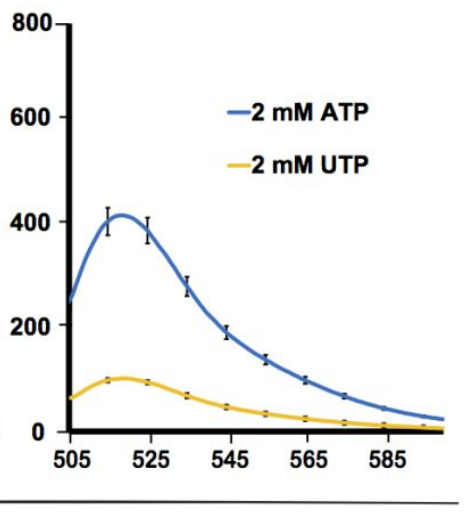

Figure S-4: Analysis of the specificity of the ARTS-R2.

A) Specificity of ARTS-R2 with $2 \mathrm{mM}$ ATP and 2mM CTP. B) Specificity of the ARTS-R2 with $2 \mathrm{mM}$ ATP and $2 \mathrm{mM} \mathrm{GTP}$. C) Specificity of the ARTS-R2 with $2 \mathrm{mM}$ ATP and $2 \mathrm{mM}$ UTP. The ARTS-R2 was prepared for the assay by heating at $95^{\circ} \mathrm{C}$ for 5 mins, and then cooling down to $25^{\circ} \mathrm{C}$ over 30 minutes. Four samples of $250 \mathrm{nM}$ ARTS-R2 were prepared in a final volume of $500 \mu \mathrm{L}$ in $10 \mathrm{mM}$ Tris- $\mathrm{HCl}$, with $6 \mathrm{mM} \mathrm{MgCl}_{2}, \mathrm{pH}=8.4$. Next, $2 \mathrm{mM}$ of each nucleotide (ATP, GTP, CTP and UTP) was added to the respective sample. Following this, the molecule was transferred to a quartz cuvette and the fluorescence intensity of 2mM ATP, GTP, CTP and UTP was measured. The fluorescence spectra were measured using excitation wavelength of the 6-FAM fluorophore $\lambda_{\mathrm{ex}}=495 \mathrm{~nm}$, and thus emission was scanned between $\lambda_{\mathrm{em}}=505-600 \mathrm{~nm}$. The results show high fluorescence intensity in the presence of ATP nucleotides, and low fluorescence intensity in the presence of GTP, CTP, and UTP nucleotides, demonstrating that the specificity of the ATP aptamer in the ARTS-R2. 

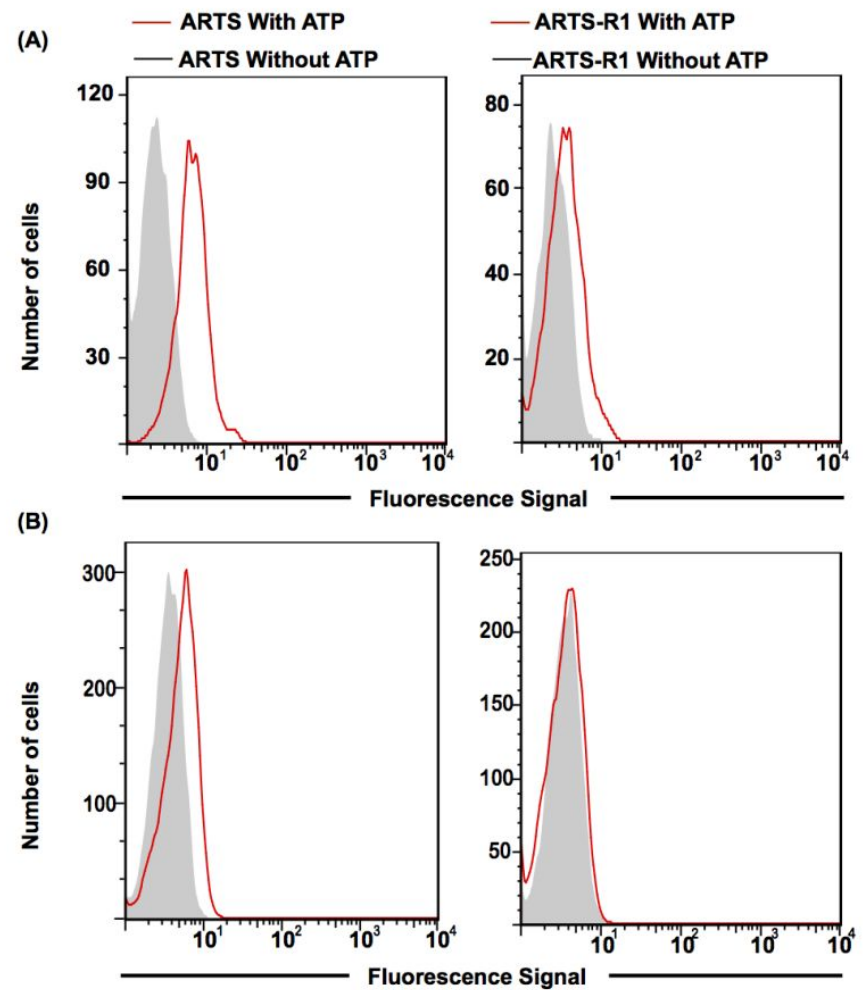

(C)

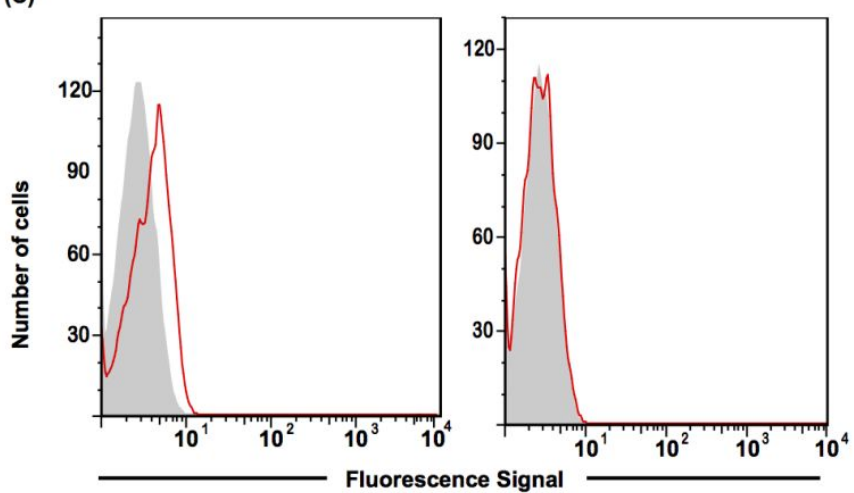

(D)

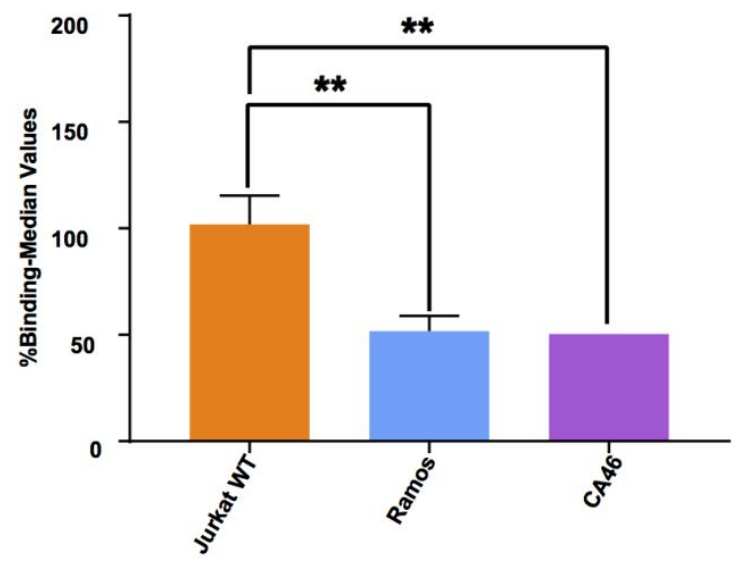


Figure S-5: Analysis of specificity of ARTS compared with ARTS-R1 with different cell lines.

A) Analysis of specificity of the anti-CD3E aptamer in the ARTS compared with ARTS-R1 control in the absence (black line) and presence of $500 \mu \mathrm{M}$ ATP (red line) with Jurkat E6.1

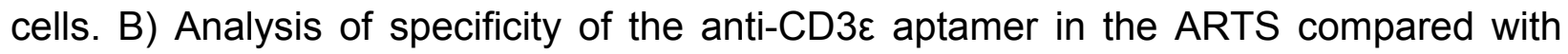
ARTS-R1 control in the absence and presence of $500 \mu \mathrm{M}$ ATP with Ramos cells. C)

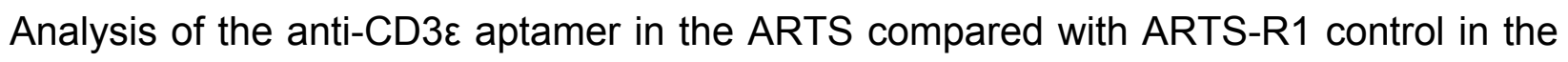
absence and presence of $500 \mu \mathrm{M}$ ATP with CA46 cells. D) Overall binding ratio using ARTS-R1 as background signal comparing Jurkat E6.1 cells to Ramos and CA46 cell lines. All constructs were prepared for the assay by heating at $95^{\circ} \mathrm{C}$ for 5 mins to denature undesirable secondary structures followed by to $25^{\circ} \mathrm{C}$ for 30 minutes. Next, $75 \mu \mathrm{L}$ of the construct at a final concentration of $100 \mathrm{nM}$, was incubated with $75 \mu \mathrm{L}$ of $1 \times 10^{5}$ Jurkat E6.1, Ramos or CA46 cells for one hour. $500 \mu \mathrm{M}$ ATP was added to respective samples and similar volume of CSB buffer was added to the other samples. Binding of each aptamer was analyzed using flow cytometry by counting 5000 events. As a positive

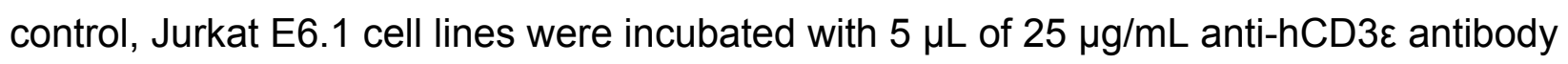
(PE Conjugated Mouse $\operatorname{lgG}_{1}$, R\&D System) or $2 \mu \mathrm{L}$ of $200 \mu \mathrm{g} / \mathrm{mL}$ isotype control (PE Mouse $\lg G_{1}, K, B D$ Biosciences) for 30 minutes on ice, followed by a one-time wash with $2 \mathrm{~mL}$ of RPMI-1640 medium and reconstituted in $250 \mu \mathrm{L}$ RPMI-1640 medium. Binding events were monitored in FL1 Green (515-545nm) for the aptamer and in FL2 Yellow (565-605 nm; 564-606 nm) for the antibody, counting 5000 events using flow cytometry. 

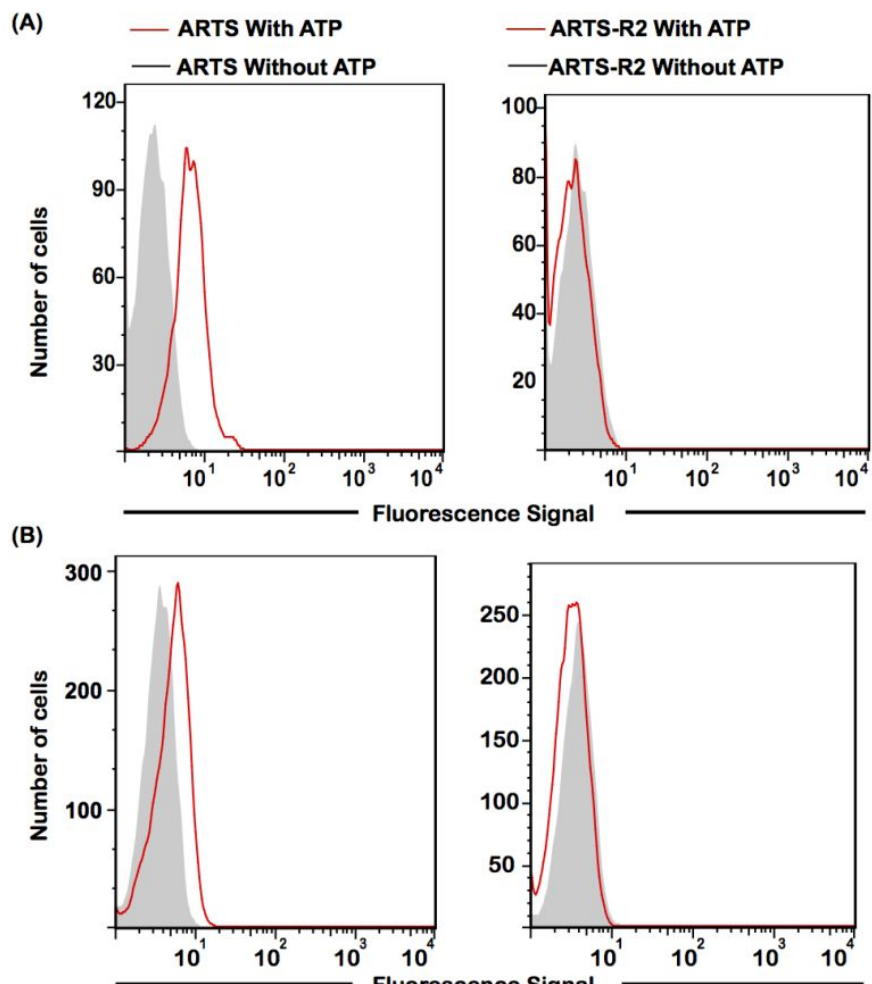

(C)

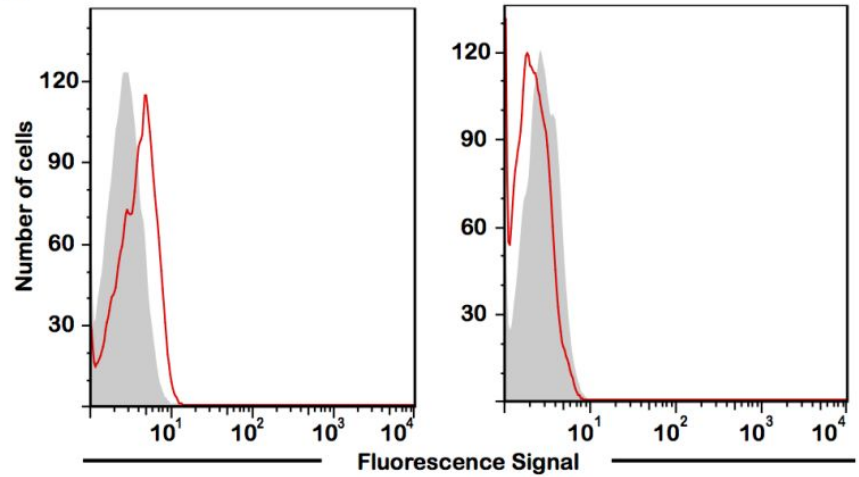

(D)

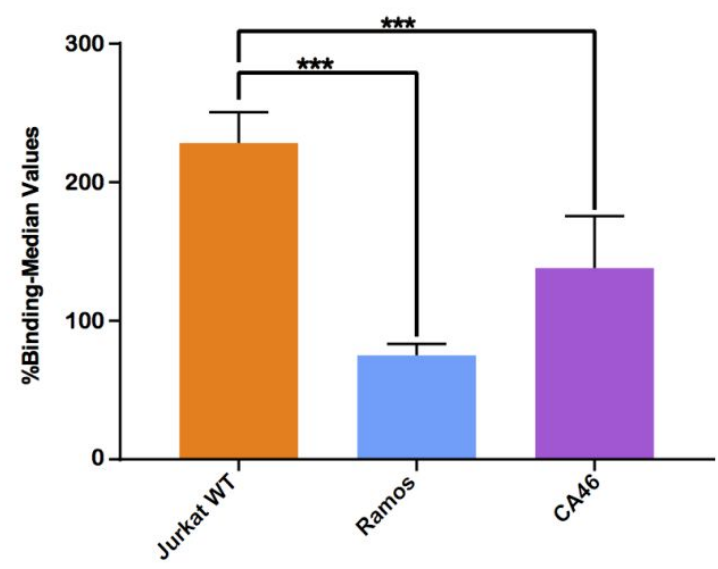


Figure S-6: Analysis of specificity of ARTS compared with ARTS-R2 with different cell lines.

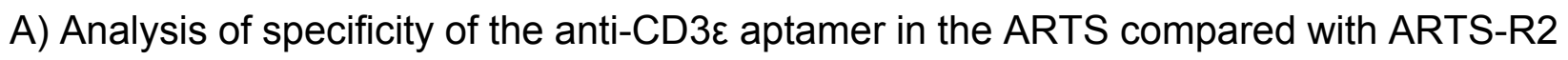
control in the absence (black line) and presence of $500 \mu \mathrm{M}$ ATP (red line) with Jurkat E6.1 cells. B) Analysis of specificity of the anti-CD3E aptamer in the ARTS compared with ARTS-R2 control in the absence and presence of $500 \mu \mathrm{M}$ ATP with Ramos cells. C)

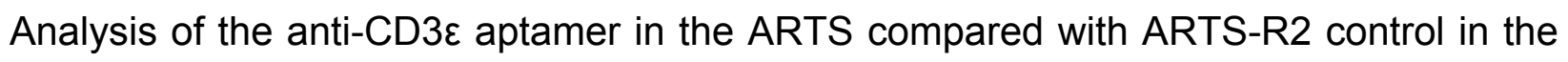
absence and presence of $500 \mu \mathrm{M}$ ATP with CA46 cells. D) Overall binding ratio using ARTS-R2 as background signal comparing Jurkat E6.1 cells to Ramos and CA46 cell lines. All constructs were prepared for the assay by heating at $95^{\circ} \mathrm{C}$ for 5 mins to denature undesirable secondary structures and then cooling to $25^{\circ} \mathrm{C}$ for 30 minutes. Then, a $75 \mu \mathrm{L}$ of the construct with a final concentration of $100 \mathrm{nM}$, was incubated with $75 \mu \mathrm{L}$ of $1 \times 10^{5}$ Jurkat E6.1, Ramos or CA46 cells for one hour. $500 \mu \mathrm{M}$ ATP was added to respective samples and similar volume of CSB buffer was added to the other samples. Binding of each aptamer was analyzed using flow cytometry by counting 5000 events. As a positive

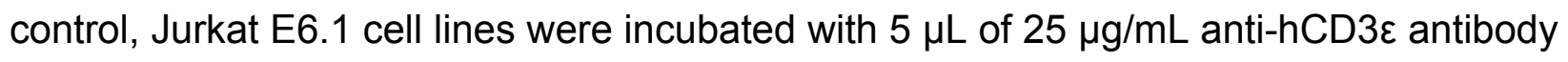
(PE Conjugated Mouse $\operatorname{lgG}_{1}, R \& D$ System) or $2 \mu \mathrm{L}$ of $200 \mu \mathrm{g} / \mathrm{mL}$ isotype control (PE Mouse $\lg G_{1}, K, B D$ Biosciences) for 30 minutes on ice, followed by a one-time wash with $2 \mathrm{~mL}$ of RPMI-1640 medium and reconstituted in $250 \mu \mathrm{L}$ RPMI-1640 medium. Binding events were monitored in FL1 Green (515-545nm) for the aptamer and in FL2 Yellow (565-605 nm; 564-606 nm) for the antibody, counting 5000 events using flow cytometry. 